\title{
Multi temporal scale variations of summer precipitation in wet seasons over China and their association with $500 \mathrm{mb}$ geopotential height
}

\author{
Zhenhao Bao ${ }^{1}$, Han-Ru Cho ${ }^{1}$, Hengchun $\mathrm{Ye}^{2, *}$ \\ ${ }^{1}$ Department of Physics, University of Toronto, Toronto, Ontario M5S 1A1, Canada \\ ${ }^{2}$ Department of Geography and Urban Analysis, California State University, Los Angeles, 5151 State University Drive, \\ Los Angeles, California 90032-8222, USA
}

\begin{abstract}
Multi scale characteristics of summer precipitation variation were studied using rotated principle component analysis and wavelet analysis on 76 stations for the period 1968-1997. We found 2 significant precipitation periods in northern and southern China corresponding to the movement of the East Asian summer monsoon. The 2 precipitation periods are characterized by a continuous $3 \mathrm{~d}$ mean precipitation higher than $10 \mathrm{~mm}$ in northern China during early July to late August and higher than $20 \mathrm{~mm}$ in southern China during early May to late June. The precipitation amounts in the first half of August over northern China and second half of June over southern China are the major contributors to the total precipitation during the 2 rainy periods, respectively. In addition, a weekly time scale precipitation variation of about $7.2 \mathrm{~d}$ during the first half of August over northern China and an intraseasonal time scale of $25 \mathrm{~d}$ during the second half of June over southern China are evident during wet seasons. Case studies for 2 extreme wet seasons over northern China in 1994 and 1996 show that weekly time scale precipitation is associated with a $500 \mathrm{mb}$ anomaly over the Sea of Japan during July to August. The 2 wet seasons over southern China in 1968 and 1994 show that intraseasonal time scale precipitation is closely associated with $500 \mathrm{mb}$ geopotential height over the tropical western Pacific during May to June.
\end{abstract}

KEY WORDS: Summer precipitation - Rainy season - Monsoon - Wavelet analysis - China · Atmospheric circulation

Resale or republication not permitted without written consent of the publisher

\section{INTRODUCTION}

The Asian monsoon is a critical water resource in Southeast Asia, and it significantly influences agricultural activities in the area. The Asian monsoon, including the South Asian and the East Asian monsoon, is an integral component of the global climate system that strongly interacts with the El Niño/ Southern Oscillation (ENSO) (e.g. Yasunari 1991, Webster \& Yang 1992, Lau \& Yang 1996). Of these 2 monsoons, the East Asian monsoon system is the more complex due to its large geographical extent. The

${ }^{*}$ Corresponding author:. E-mail: hengchun.ye@calstatela.edu
East Asian monsoon has 2 branches: the southern and northern branches. The southern branch of the East Asia monsoon is centered in the South China Sea (SCS), with tropical circulation features starting in May and influencing rainfall over southern China. The northern branch of the monsoon is located over central China, Japan, and Korea in June and moves to northern China in July (e.g. Tao \& Chen 1987, Murakami \& Matsumoto 1994).

One of the most important parameters used to describe the summer monsoon is the precipitation total. This is because a wetter summer is often accompanied by a stronger monsoon. Total summer precipitation variation over China has been linked to the ENSO, the west Pacific warm pool, and atmospheric 


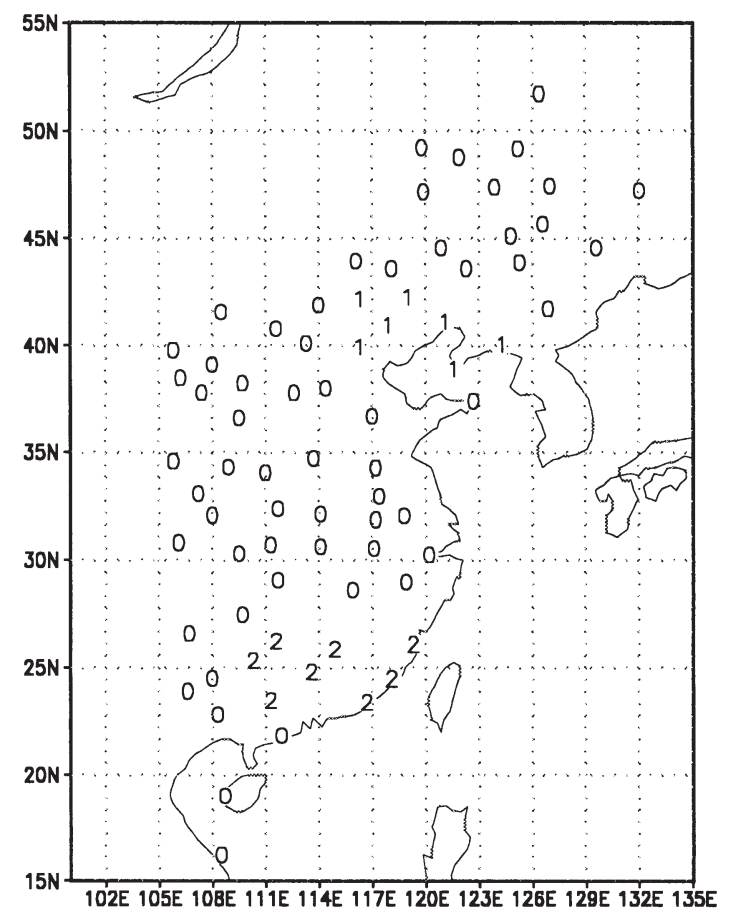

Fig. 1. Station distribution. Stations labeled 1 and 2 were used to produce area averages of $3 \mathrm{~d}$ precipitation series for northern and southern China respectively

circulation over the Eurasian continent (e.g. Wang \& Zhao 1981, Wang \& Li 1990, Ding 1991, Chen et al. 1992, Yatagai \& Yasunari 1994, 1995, Chen \& Chen 1995, Chen \& Hsu 1997, Bao \& Mikami 1998, Krishnakumar \& Lau 1998, Unda \& Yasunari 1998). However, the multi scale characteristics of summer precipitation variation over northern and southern China and their associated atmospheric circulation mechanisms are still not clear. Since the summer monsoon migrates from south to north, understanding the associations and differences between precipitation structures linked to the southern and northern branches of the East Asian monsoon is important for regional precipitation prediction.

The purpose of the present research is to examine the characteristics of monsoon precipitation associated with the southern and northern branches of the East Asian monsoon and their connections to atmospheric circulation patterns, especially during extreme wet seasons. The paper is organized as follows: data and methods are described in Section 2. Multi time scale characteristics of summer precipitation are revealed in Section 3. Section 4 presents the $500 \mathrm{mb}$ geopotential height anomalies associated with the weekly and intraseasonal time scale precipitation variations in wet seasons. Finally, conclusions are given in Section 5.

\section{DATA AND METHODS}

\subsection{Data}

Daily precipitation records at 76 stations over eastern China from January 1, 1968, to December 31, 1997 , were used in this study (Fig. 1). This precipitation data set was originally distributed by the State Meteorological Agency of PR China and the US Department of Energy (Tao et al. 1991). The data set used in this study is directly from Dr. A. N. Samel (Dept. of Geography, Bowling Green University, DH, USA) and Dr. X.-Z. Liang (Illinois State Water Survey, University of Illinois, Champagne, IL, USA) and was used in their previous monsoon study (Samel et al. 1999).

Daily mean $500 \mathrm{mb}$ geopotential heights during the 1968-1997 summer season (May-August) were obtained from the reanalysis products of the National Center for Environmental Prediction (NCEP; Kalnay et al. 1996). The geopotential heights have a resolution of $2.5^{\circ}$ latitude by $2.5^{\circ}$ longitude, and the grids over the entire eastern Northern Hemisphere $\left(20^{\circ} \mathrm{E}\right.$ to $\left.140^{\circ} \mathrm{W}\right)$ were selected.

\subsection{Methods}

First, to reduce data dimension, time series of $3 \mathrm{~d}$ mean precipitation were derived from daily records for 1968-1997 at each station. The reason for using $3 \mathrm{~d}$ mean precipitation instead of pentad mean precipitation is to retain weekly signals in addition to longer time scale variations. Each year is considered to have $365 \mathrm{~d}$, February 29 in leap years being removed in this study. Daily precipitation from January 1 to December 26 is first formed into 120 periods of $3 \mathrm{~d}$, and the 121st point for a given year is then derived from a $5 \mathrm{~d}$ average precipitation from December 27-31. Thus, each year contains 121 units of $3 \mathrm{~d}$ precipitation recorded as P1 (January 1 to 3) to P121 (December 27 to 31).

Second, rotated principal component analysis (RPCA) was used to reveal regional variation patterns of climatological $3 \mathrm{~d}$ precipitation variability. The spatial patterns derived by RPCA are believed to be robust and physically realistic (Richman 1986, 1987). PCA is first applied to the $30 \mathrm{yr}$ average values of P1 to P121 ( $\mathrm{n}=$ 121) for the 76 stations, then Varimax rotation is applied to the retained first 5 PCs that explain $79.2 \%$ of the total variance of the $3 \mathrm{~d}$ precipitation data. The cutoff between the fifth and sixth PCs is based on a significant break between the two.

Third, the 5 wettest seasons out of the $30 \mathrm{yr}$ study period were selected for northern and southern China respectively. Wavelet transform (WT) was applied to the area-averaged $3 \mathrm{~d}$ mean precipitation time series 
(5 wet years' average) over northern and southern China to reveal multi time scale characteristics of wet seasons' summer precipitation. The specific areas used in the area average for northern and southern China were defined by the spatial patterns of PCs.

WT can detect features not only in frequency space but also temporal localization and thus is highly suitable for identifying non-linear fluctuations in the precipitation time series. Since the introduction of WT in atmospheric science by Mahrt (1991), it has become a popular and powerful tool in researching atmosphere and climate variability (e.g. Gamage \& Blumen 1993, Meyers et al. 1993, Weng \& Lau 1994, Torrence \& Compo 1998).

WT decomposes function $f(t)$ into terms of some elementary functions, $\varphi_{b, a}(t)$, derived from a 'mother wavelet', $\varphi(t)$, by dilation and translation:

$$
\varphi_{b, a}(t)=\frac{1}{a^{1 / 2}} \cdot \varphi\left(\frac{t-b}{a}\right)
$$

where $b$ denotes the position (translation) and $a(>0)$ the scale (dilation) of the wavelet. $\varphi_{b, a}(t)$ is called the 'daughter wavelet'.

WT of function $f(t)$ with respect to the analysis of wavelet $\varphi(t)$ may be defined as a convolution integral:

$$
W(b, a)=\frac{1}{a^{1 / 2}} \cdot \int \varphi^{*}\left(\frac{t-b}{a}\right) \cdot f(t) \mathrm{d} t
$$

$W(b, a)$ is the WT of $f(t) . \varphi^{*}$ is a complex conjugate of $\varphi$ defined on the open 'time and scale' real $(b, a)$ plane. The function $f(t)$ can be formally reconstructed from wavelet coefficients by the inversion formula (Lau \& Weng 1995):

$$
f(t)=\frac{1}{c_{\varphi}} \cdot \int \frac{\mathrm{d} a}{a} \int \frac{1}{a^{1 / 2}} \cdot \varphi\left(\frac{t-b}{a}\right) \cdot w_{b, a} \cdot d b
$$

where:

$$
C_{\varphi}=\int_{0}^{\infty} \frac{|\hat{\varphi}(\omega)|}{\omega} \cdot \mathrm{d} \omega \leq+\infty
$$

and $\hat{\varphi}$ is the Fourier transform of $\varphi(t)$. In Eq. (3), the filter analysis of function $f(t)$ may use the real part of $W(b, a)$.

The continuous Morlet wavelet:

$$
\varphi(t)=\alpha^{-1 / 4} \cdot \mathrm{e}^{i \cdot \omega \cdot t} \cdot \mathrm{e}^{-t^{2} / 2}
$$

is used in the present application. The procedure for calculating the Morlet WT is described by Morlet (1983) and Torrence \& Compo (1998). The Morlet WT has an edge effect at the beginning and end of the time domain. Because the time scale displays of the wavelet coefficients are conical in shape, some information will be lost at the edges of the frames. In this study, the Morlet WT is applied to the entire year's 3 d mean precipitation from P1 to P121, and the time scales for the Morlet WT were taken from 1.0 to 11.3 (6.0-67.8 d).
Since we are only interested in the results for summer precipitation (P41-80), the edge effects are avoided. The details of the calculation procedure used in this study are listed in Appendix 1.

The statistical significance of the WT results was tested by using WT on 1000 Monte Carlo simulated red-noise time series having the same mean, variance, and autocorrelation (lag 1) as the original area-averaged time series. The $95 \%$ confidence value is the 50th highest corresponding wavelet power. If the peak in the wavelet spectrum was higher than this $95 \%$ confidence value, the corresponding local frequency was considered to be statistically significant (Torrence \& Compo 1998).

Fourth, the filtered 3 d precipitation time series, each containing a specific time scale variation component, were correlated to $500 \mathrm{mb}$ geopotential heights for 2 selected extreme wet seasons for northern and southern China separately. The correlation coefficients map revealed $500 \mathrm{mb}$ circulation anomalies associated with precipitation variation at different time scales.

In defining statistically significant correlations, autocorrelation in the time series was taken into account by estimating the equivalent sample size (the true independent sample size). The equivalent sample size is the actual sample size divided by the decorrelation time $(t)$ (von Storch \& Zwiers 1999). The decorrelation time for correlation between 2 time series was estimated using:

$$
t=1+2 \sum_{k=1}^{k=n-1}\left(1-\frac{k}{n}\right) \rho_{x}(k) \rho_{y}(k)
$$

where $\rho_{x}(k)$ and $\rho_{y}(k)$ are the autocorrelation function of the 2 time series at lag $k$. The equivalent sample size was used to estimate the statistically significant levels in all correlation analyses.

\section{MULTI TIME SCALE CHARACTERISTICS OF SUMMER PRECIPITATION}

Among the 5 resulting PCs from RPCA, the first 2 precipitation spatial patterns represent summer precipitation variation (Fig. 2). The spatial pattern of PC1 has a positive center over northern China around $37-45^{\circ} \mathrm{N}, 115^{\circ}-125^{\circ} \mathrm{E}$ and a negative center over central China (Fig. 2a). This mode accounts for $59.3 \%$ of the total $3 \mathrm{~d}$ precipitation variance and has large positive values during early July to late August (Fig. 3a). Clearly, this pattern represents East Asian summer monsoon rainfall over northern China, which mainly comes from the influence of the northern branch of the East Asian monsoon (e.g. Lau et al. 1988, Chen et al. 1992, Ding 1992, 1994). 
a. PC1

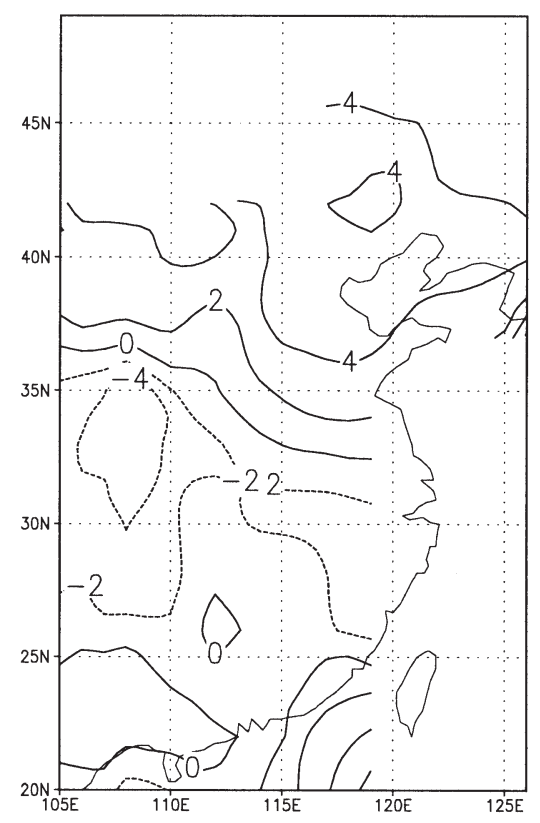

b. PC2

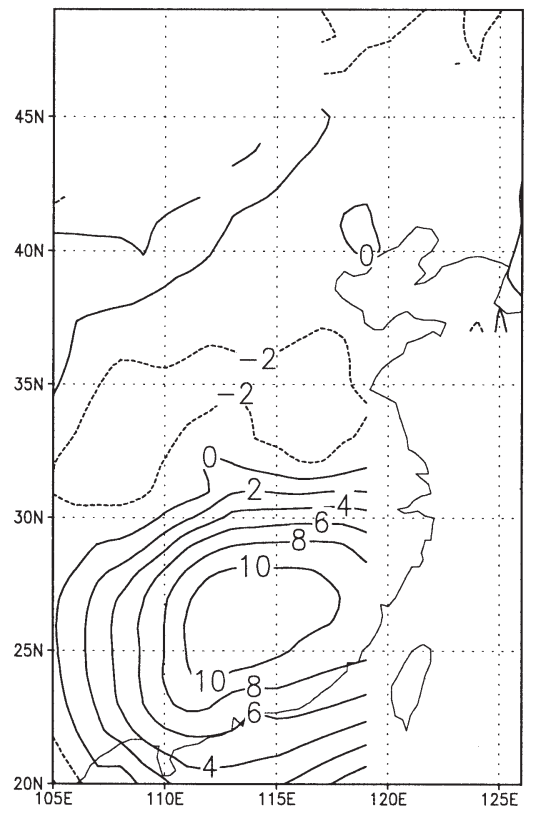

Fig. 2. The spatial patterns for the first 2 PCs produced from rotated principle component analysis (RPCA) of the 121 units of $3 \mathrm{~d}$ precipitation (P1-121). Loading values are from RPCA on $30 \mathrm{yr}(1968-1997)$ of $3 \mathrm{~d}$ mean precipitation, $p$, multiplied by 100

The spatial component of PC2 has a positive center over southern China at around $20-30^{\circ} \mathrm{N}, 110-120^{\circ} \mathrm{E}$, and a negative center over the lower reaches of the Yangtze River Valley (central China; Fig. 2b). This mode accounts for $10.5 \%$ of the total $3 \mathrm{~d}$ mean precipitation variance. The highest positive values of PC2 occur during April to late June with a short period of weak peak values occurring about 10 d later (Fig. 3b). The time period including the largest values corresponds to the period of the East Asian summer monsoon over southern China as suggested by Lau et al. (1988).

To further examine the associations and multi scale characteristics of regional precipitation over northern and southern China, the time series of area-averaged precipitation were developed for these 2 regions separately. Seven stations over northern China and 9 stations over southern China (Table 1, Fig. 1), located within the major centers of PC1 and PC2 respectively, were selected to derive the regional precipitation series. Two time series of 3 d mean area-averaged precipitation (30 yr averaged) in northern and southern China are shown in Fig. 4. The time evolutions of these 2 series resemble those of the first 2 PCs shown in Fig. 3, and the correlation coefficients between areaaveraged precipitation and the corresponding PC time series are 0.94 and 0.91 for northern and southern China respectively ( $p=0.01)$.

The $3 \mathrm{~d}$ area-averaged precipitation over northern China from late June to late August (P59-78) is greater than $10 \mathrm{~mm}$. This period corresponds to the development and mature stages of the northern branch of the East Asian monsoon (Ding 1991, 1994, Samel et al. 1999) and is defined as the 'rainy season' in this study. An obvious rainy season over southern China occurs during May to late June (P41-60), which is characterized by greater than $20 \mathrm{~mm}$ of $3 \mathrm{~d}$ area-averaged

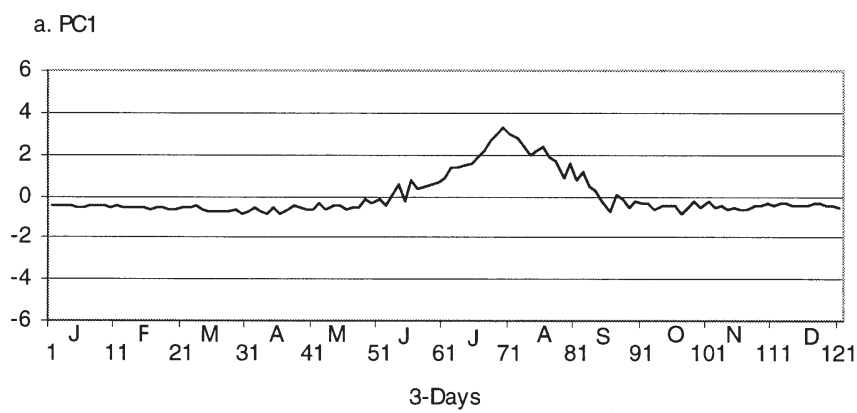

b. PC2

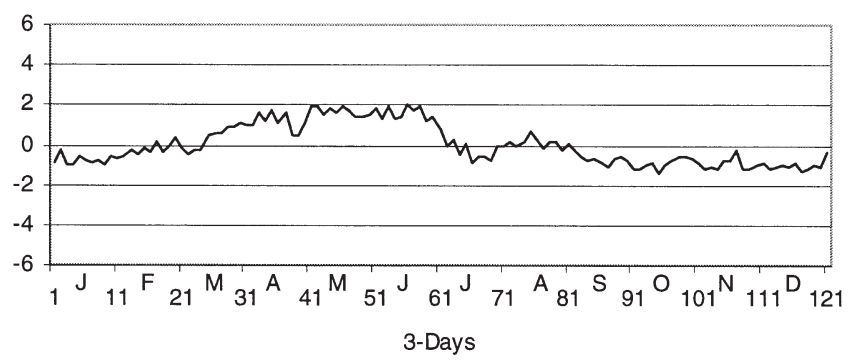

Fig. 3. Time series of the first 2 PCs 
Table 1. Stations used to derive area-averaged $3 \mathrm{~d}$ precipitation for northern and southern China (stations marked 1 and 2 in Fig. 1, respectively)

\begin{tabular}{|lcc|}
\hline Region code & Latitude $\left({ }^{\circ} \mathrm{N}\right)$ & Longitude $\left({ }^{\circ} \mathrm{E}\right)$ \\
\hline Northern China & & \\
54208 & 42.18 & 116.30 \\
54218 & 42.27 & 118.97 \\
54337 & 41.13 & 121.10 \\
54423 & 40.97 & 117.93 \\
54497 & 40.05 & 124.30 \\
54511 & 39.93 & 116.28 \\
54662 & 38.90 & 121.56 \\
Southern China & & \\
57866 & 26.23 & 111.62 \\
57957 & 25.33 & 110.30 \\
57993 & 25.85 & 114.90 \\
58847 & 26.08 & 119.28 \\
59082 & 24.80 & 113.60 \\
59134 & 24.48 & 118.07 \\
59265 & 23.48 & 111.30 \\
59287 & 23.13 & 113.32 \\
59316 & 23.40 & 116.67 \\
\hline
\end{tabular}

a. Northern China

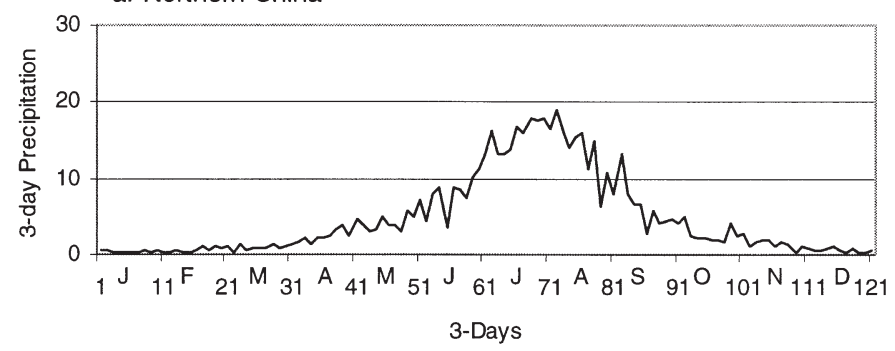

b. Southern China

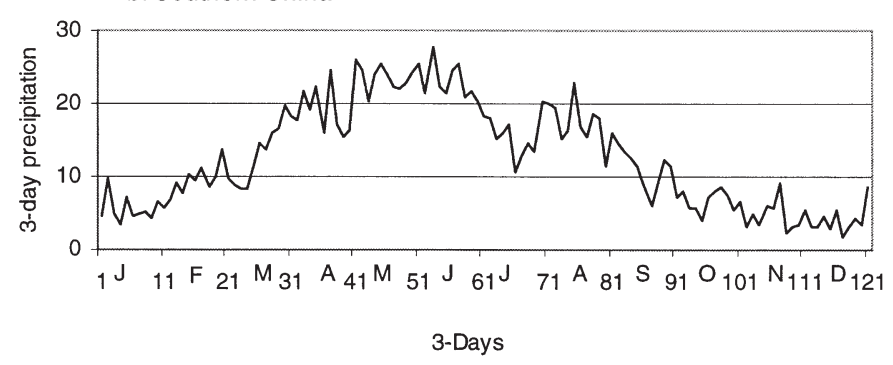

Fig. 4. The average $3 \mathrm{~d}$ mean precipitation over (a) northern and (b) southern China for the $30 \mathrm{yr}$ study period

precipitation. Therefore, the rainy season period is P61-80 (July-August) in northern China and P41-60 (May-June) in southern China. The $3 \mathrm{~d}$ mean precipitation in southern China is much higher than that in northern China. The difference in quantity of precipitation in these 2 regions is associated with different geographical settings and background monsoon circulation.

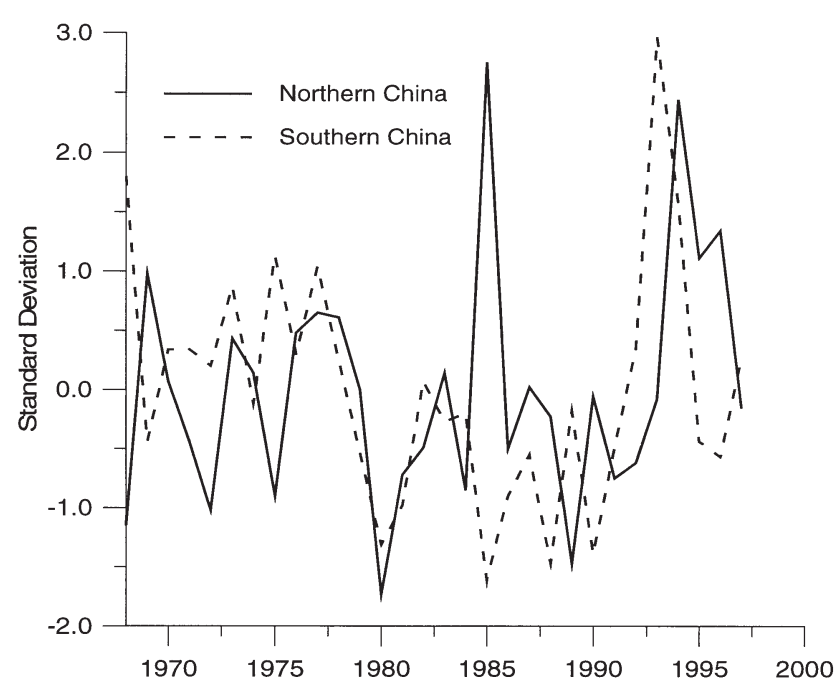

Fig. 5. Time series of standard deviations for July-August (P61-80) precipitation over northern China and May-June (P41-60) precipitation over southern China

The standard deviations of rainy season total precipitation for northern (P61-80) and southern (P41-60) China for the $30 \mathrm{yr}$ study period are displayed in Fig. 5. They seem to fluctuate at the same phases at decadal time scales, with below-normal precipitation evident during the 1980s. This feature reflects the decadal time scale variability suggested by other studies (Nitta \& Hu 1996, Samel et al. 1999). The correlation coefficient of $5 \mathrm{yr}$ moving averages of rainy season precipitation totals between northern and southern China is 0.52 for the sample size of 26 . However, due to high autocorrelation in the moving-average time series, the actual independent sample size (the equivalent sample size) is estimated to be 6.2. Thus they are not statistically significantly correlated.

The extreme wet and dry seasons over northern and southern China were identified using the standard deviations of rainy season precipitation shown in Fig. 5. We found 7 (6) wet and 10 (9) dry cases in northern China (southern China) based on cutoff values of 0.5 or -0.5 . In this study, we select the 5 wettest and 5 driest seasons (Table 2). Statistically significant precipitation differences ( $\mathrm{p}=0.05 ; t=2.3)$ between the 5 wettest and 5 driest seasons during P72-75 (the first half of August) over northern China and during P54-58 (the second half of June) over southern China were found based on Student's 2-tailed $t$-tests (Fig. 6). This suggests that precipitation during the first half of August and during the second half of June is responsible for anomalous wet or dry conditions over northern and southern China, respectively. Time series of $3 \mathrm{~d}$ mean precipitation during P72-75 over northern China and during P54-58 over southern China are shown in Fig. 7. 
Table 2. Precipitation (Precip.) total and standard deviations for the selected 5 wettest and driest seasons for (a) northern China in July-August (P61-80) and the first half of August (P72-75) and (b) southern China in May-June (P41-60) and the second half of June (P54-58)

\begin{tabular}{|c|c|c|c|c|c|}
\hline \multirow[t]{2}{*}{ (a) Northern China } & \multicolumn{3}{|c|}{ July-August (P61-80) } & \multicolumn{2}{|c|}{ First half of August (P72-75) } \\
\hline & Year & Precip. & SD & Precip. (mm) & SD \\
\hline \multirow[t]{5}{*}{ Wet } & 1969 & 371.4 & 0.98 & 91.9 & 0.80 \\
\hline & 1985 & 509.2 & 2.75 & 76.4 & 0.35 \\
\hline & $1994^{\mathrm{a}}$ & 485.4 & 2.44 & 135.0 & 2.06 \\
\hline & 1995 & 381.4 & 1.11 & 110.8 & 1.35 \\
\hline & $1996^{\mathrm{a}}$ & 399.5 & 1.34 & 150.4 & 2.51 \\
\hline Average & & 429.4 & 1.92 & 112.9 & 1.41 \\
\hline \multirow[t]{5}{*}{ Dry } & 1968 & 206.6 & -1.14 & 29.9 & -1.01 \\
\hline & 1972 & 216.1 & -1.02 & 48.3 & -0.47 \\
\hline & 1975 & 225.3 & -0.90 & 44.6 & -0.58 \\
\hline & 1980 & 160.6 & -1.72 & 38.0 & -0.77 \\
\hline & 1989 & 180.8 & -1.47 & 11.7 & -1.54 \\
\hline Average & & 197.9 & -1.25 & 34.5 & -0.87 \\
\hline \multirow[t]{2}{*}{ (b) Southern China } & \multicolumn{3}{|c|}{ May-June (P41-60) } & \multicolumn{2}{|c|}{ Second half of June (P54-58) } \\
\hline & Year & Precip. (mm) & SD & Precip. (mm) & $\mathrm{SD}$ \\
\hline \multirow[t]{5}{*}{ Wet } & $1968^{\mathrm{a}}$ & 615.2 & 1.79 & 304.9 & 2.96 \\
\hline & 1975 & 560.4 & 1.13 & 98.8 & -0.31 \\
\hline & 1977 & 553.0 & 1.04 & 129.4 & 0.23 \\
\hline & 1993 & 712.1 & 2.96 & 191.6 & 1.20 \\
\hline & $1994^{\mathrm{a}}$ & 596.0 & 1.56 & 290.3 & 2.74 \\
\hline Average & & 607.3 & 1.70 & 202.2 & 1.36 \\
\hline \multirow{5}{*}{ Dry } & 1980 & 358.7 & -1.31 & 18.3 & -1.50 \\
\hline & 1981 & 385.7 & -0.98 & 33.9 & -1.26 \\
\hline & 1985 & 333.8 & -1.61 & 47.4 & -1.05 \\
\hline & 1988 & 345.6 & -1.47 & 65.5 & -0.76 \\
\hline & 1990 & 352.2 & -1.39 & 86.4 & -0.44 \\
\hline Average & & 355.2 & -1.35 & 50.3 & -1.00 \\
\hline${ }^{\mathrm{a}}$ Extremely wet seaso & & & & & \\
\hline
\end{tabular}

When the 3 d mean precipitation during JulyAugust (P61-80) is compared with that of the first half of August (P72-75) over northern China for the 5 driest and 5 wettest years, they correspond quite well (Table 2). So do the precipitation amounts during May-June (P41-60) and the second half of June (P54-58). The correlation coefficient for the precipitation amounts of July-August and the first half of August over northern China is $0.66(p=0.05)$. The correlation coefficient for the precipitation amounts of May-June and the second half of June over southern China is $0.65(p=0.05)$. This further suggests that the precipitation anomalies in the first half of August and the second half of June are important dry/wet indices for northern and southern China respectively.

WT calculations are based on the 5 wet years' average of the $1213 \mathrm{~d}$ mean precipitation (an entire year) for northern and southern China respectively. The precipitation time series and the corresponding wavelet spectrum are shown for the summer season only in Figs. 8 \& 9. Time scales shorter than $10 \mathrm{~d}$ are dominant at around P64, P68 and P72-75; the WT power at $7.2 \mathrm{~d}$ is the strongest in the first half of August (P72-75) in northern China and is statistically significant at a $95 \%$ confidence level (Fig. 8b). Rainfall variation with a period of $25 \mathrm{~d}$ is dominant during May-June over southern China, and it is statistically significant at a $95 \%$ confidence level during the second half of June (P54-58; Fig. 9b). The precipitation variability at $25 \mathrm{~d}$ over southern China has been found to correspond to the SCS circulation variations at the same time scale (Unda \& Yasunari 1998). The presence of intraseasonal time scale precipitation found over southern China is consistent with earlier studies (e.g. Wang et al. 1996, Wang \& Wu 1997). 
a. Northern China

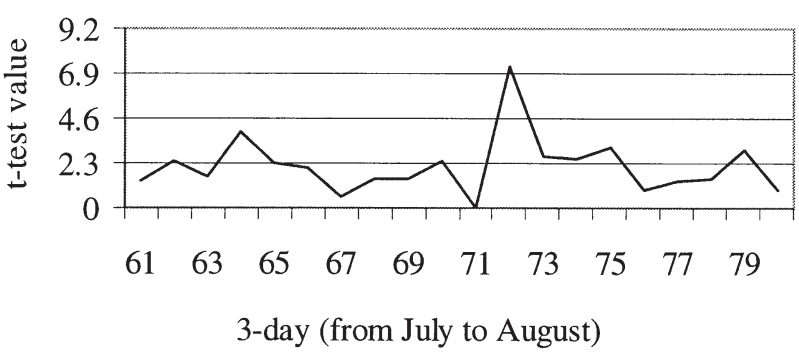

\section{b. Southern China}

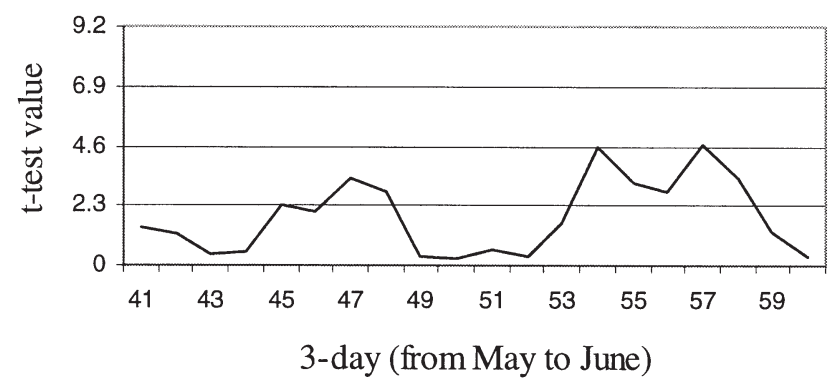

Fig. 6. Student's 2-tailed $t$-test values for the 5 wettest and 5 driest rainy seasons: (a) northern and (b) southern China

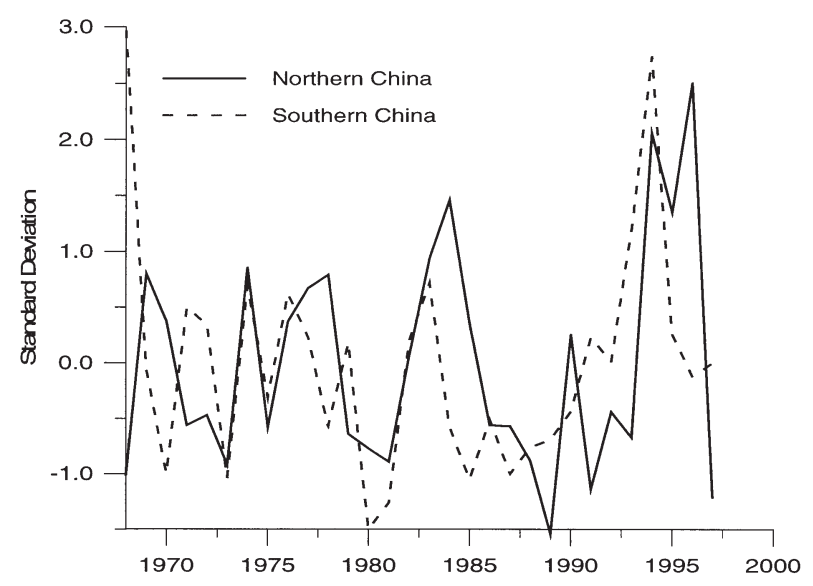

Fig. 7. Time series of standardized precipitation departures for the first half of August (P72-75) over northern China and

the second half of June (P54-58) over southern China

\section{4. $500 \mathrm{mb}$ GEOPOTENTIAL HEIGHT ANOMALIES ASSOCIATED WITH WEEKLY AND INTRASEASONAL TIME SCALE PRECIPITATION VARIATIONS}

The associations of $500 \mathrm{mb}$ geopotential height to monthly or seasonal temperature and precipitation variations over East Asia have been studied extensively (e.g. Wang \& Zhao 1981, Ye 1987, Fu \& Fletcher 1988, Yatagai \& Yasunari 1994, Liang \& Wang 1995, Nitta \& Hu 1996, Samel et al. 1999). The behavior of

\section{a. time series}

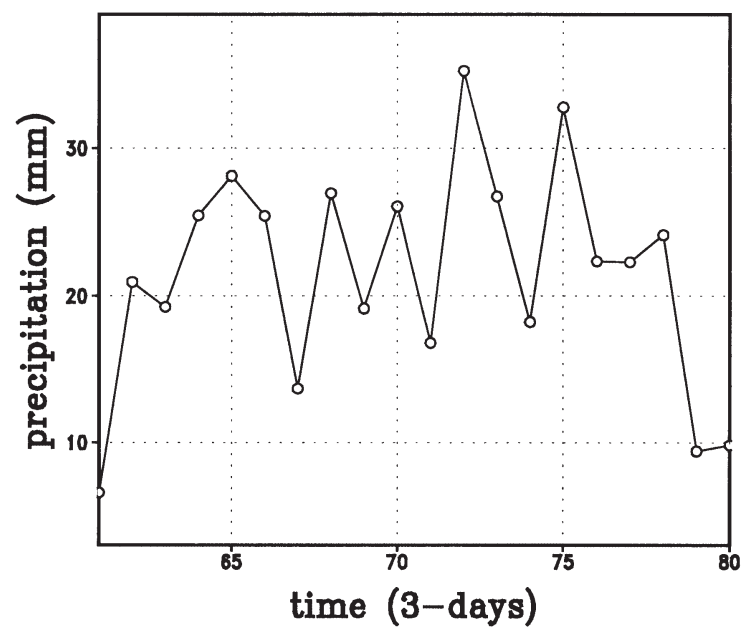

b. WT

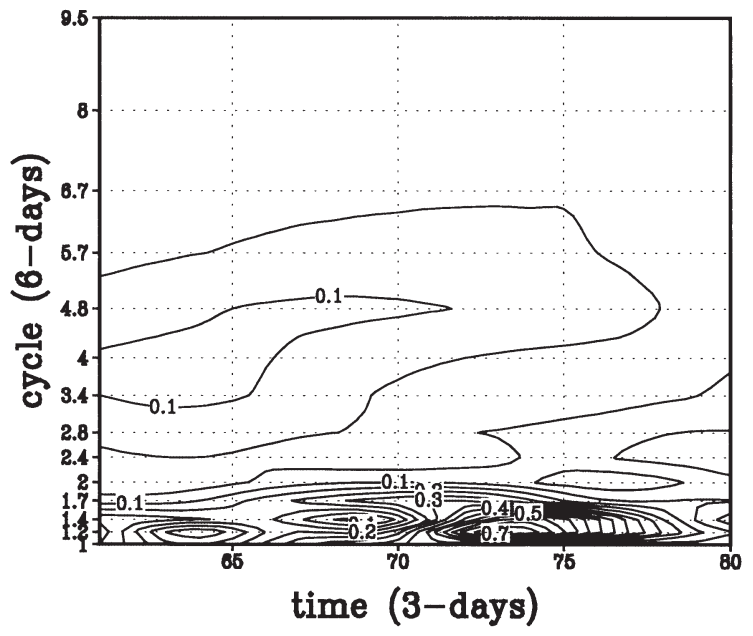

Fig. 8. (a) Three day mean precipitation over northern China averaged from the 5 wettest seasons and (b) local wavelet power spectrum from the wavelet transform (WT)

the $500 \mathrm{mb}$ geopotential height over the Eurasian continent and East Asia have been interpreted by the evolution of synoptic scale middle-latitudinal troughs (cyclones) and ridges (anticyclones) (Ding 1992, Liang \& Wang 1995). In this section, we focus on the association between $3 \mathrm{~d}$ precipitation variability at weekly (6-20 d) and seasonal (25-70 d) time scales and the $500 \mathrm{mb}$ geopotential height anomalies during northern and southern China's rainy seasons (P41-60 and P61-80 respectively).

The 3 d mean 500 mb geopotential height was computed the same way as $3 \mathrm{~d}$ precipitation. Due to complicated relationships between atmospheric circulation and precipitation, we only analyzed rainy seasons for northern and southern China for selected extremely wet years. The 2 extreme wet years for the northern Chinese rainy season are 1994 and 1995 

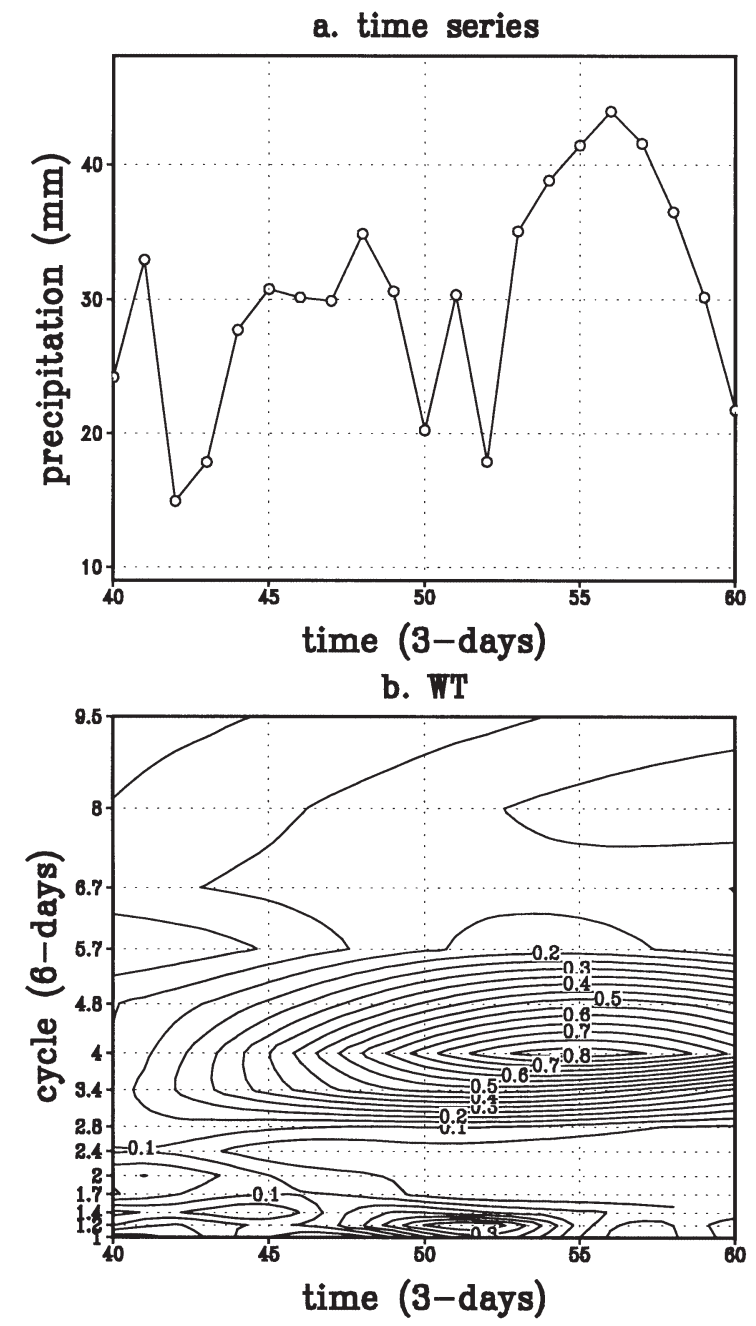

Fig. 9. (a) Three day mean precipitation over southern China averaged from the 5 wettest seasons and (b) local wavelet power spectrum from WT

and for the southern Chinese are 1968 and 1994 (the standard deviation of precipitation during rainy seasons is larger than 2.0 for these selected years; see Table 2).

The $3 \mathrm{~d}$ precipitation time series (P1-121) for these 4 selected wet years were subjected to filters to obtain the weekly and seasonal time scale variability components. The chosen filter was the real part of the Morlet wavelet (on the basis of Eq. 3 and Appendix 1), as has been used by many studies (e.g. Weng \& Lau 1994, Chapa et al. 1998, Torrence \& Compo 1998). A bandwidth of 6-70 d (6-70D) was selected and defined 6-20 d (6-20D) as weekly time scales and 25-70 d (25-70D) as intraseasonal time scales. Separate examinations of simultaneous correlation between each of these 2 time scale variations and the $500 \mathrm{mb}$ geopotential heights were performed to reveal different atmos- pheric roles in wet season precipitation activity for southern and northern China.

\subsection{Association with weekly precipitation variation over northern China in 1994 and 1996}

The standardized time series of $3 \mathrm{~d}$ mean precipitation and its filtered 6-70D, 6-20D (weekly), and 25-70D (intraseasonal) components for northern China during July-August, 1994 are displayed in Fig. 10. The $3 \mathrm{~d}$ precipitation has 2 obvious low precipitation periods during early July to early August, corresponding to the break period of the East Asian monsoon (Fig. 10). The weekly and intraseasonal time scale components show opposite phases starting in late July. The weekly time scale precipitation contributes most to the $3 \mathrm{~d}$ mean precipitation during late July (P68-71).

The correlation coefficients between each of the precipitation time series and the $500 \mathrm{mb}$ geopotential heights during 1994 are displayed in Fig. 11. The coefficients pattern of $500 \mathrm{mb}$ geopotential height correlations with the $3 \mathrm{~d}$ precipitation and the $6-70 \mathrm{D}$ filtered precipitation are very similar (Fig. 11a,b). This suggests that the $6-70 \mathrm{D}$ filtered precipitation captures the major properties of the $3 \mathrm{~d}$ precipitation variability associated with atmospheric circulation. The correlation map for the weekly precipitation component has 3 significant correlation centers: positive centers over northern central Eurasia (near Lake Baikal) and over the coast of northeast China and Korea (or the Sea of

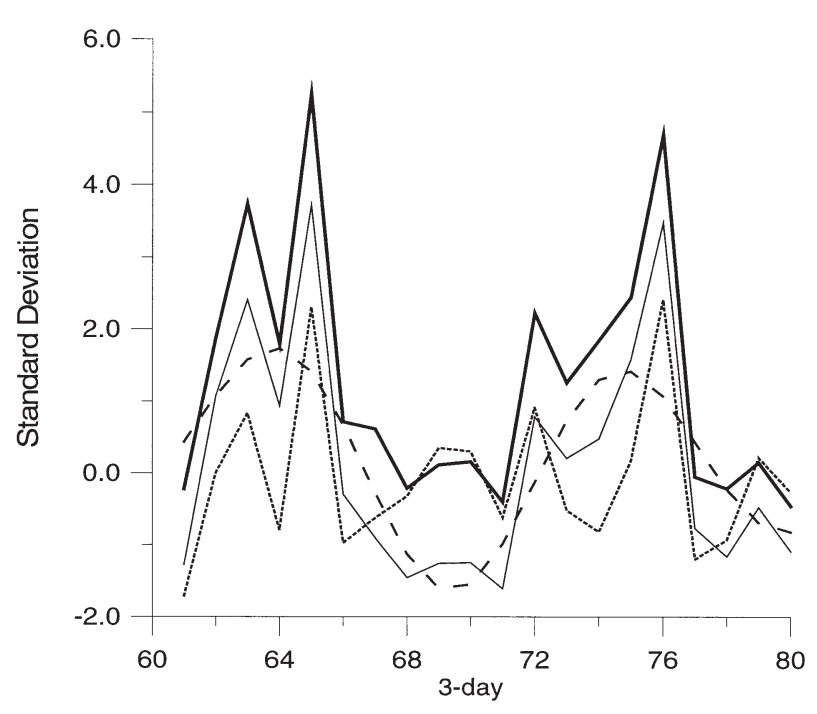

Fig. 10. Three day mean precipitation (thick solid line), 6-70D filtered (thin solid line), 6-20D (weekly; dotted line), 25-70D (intraseasonal; dashed line) precipitation during July-August (P61-80) 1994 in northern China 

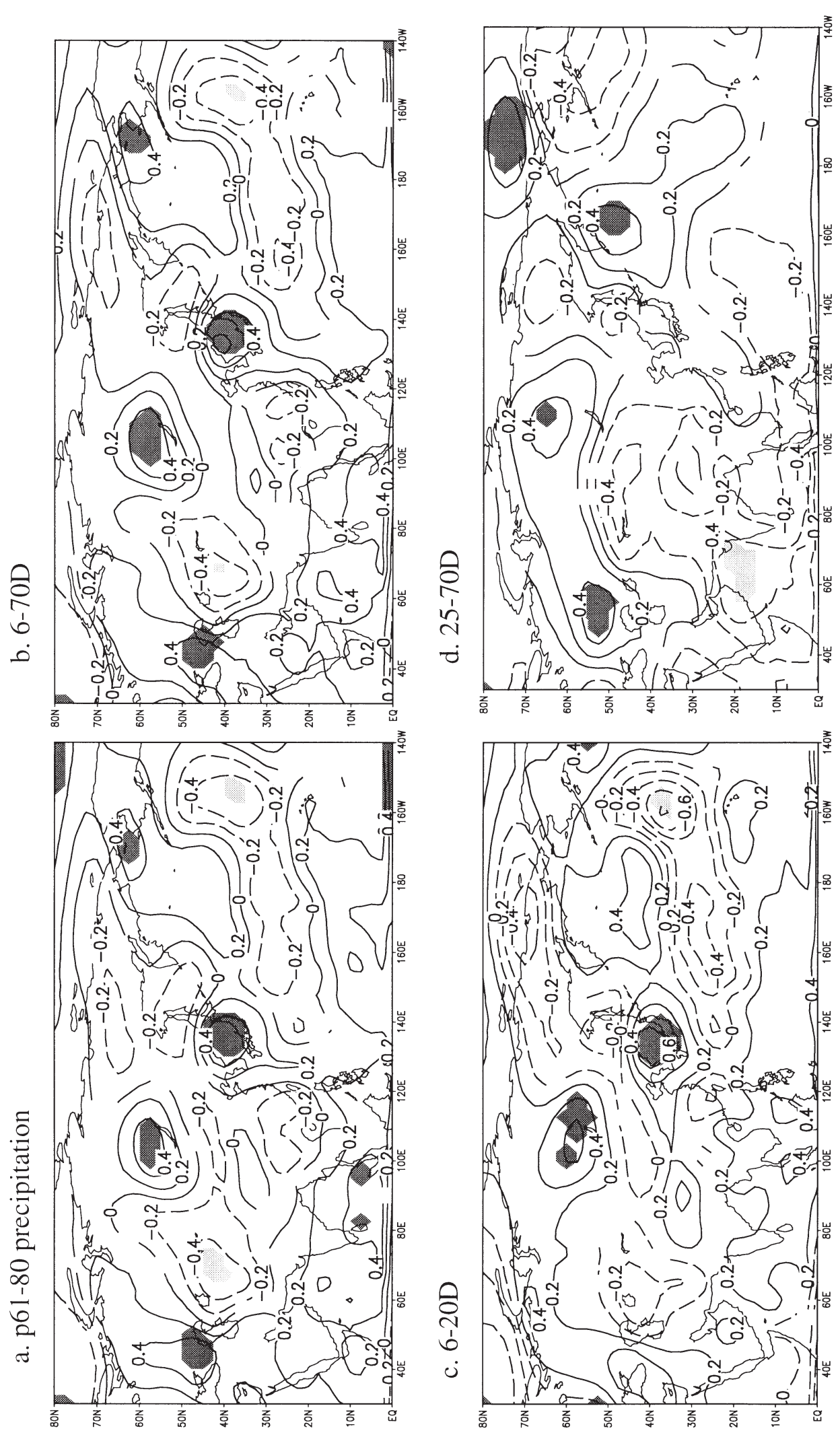

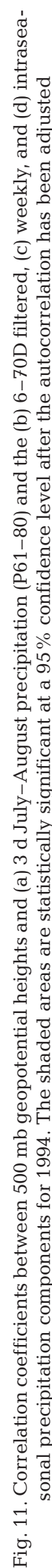




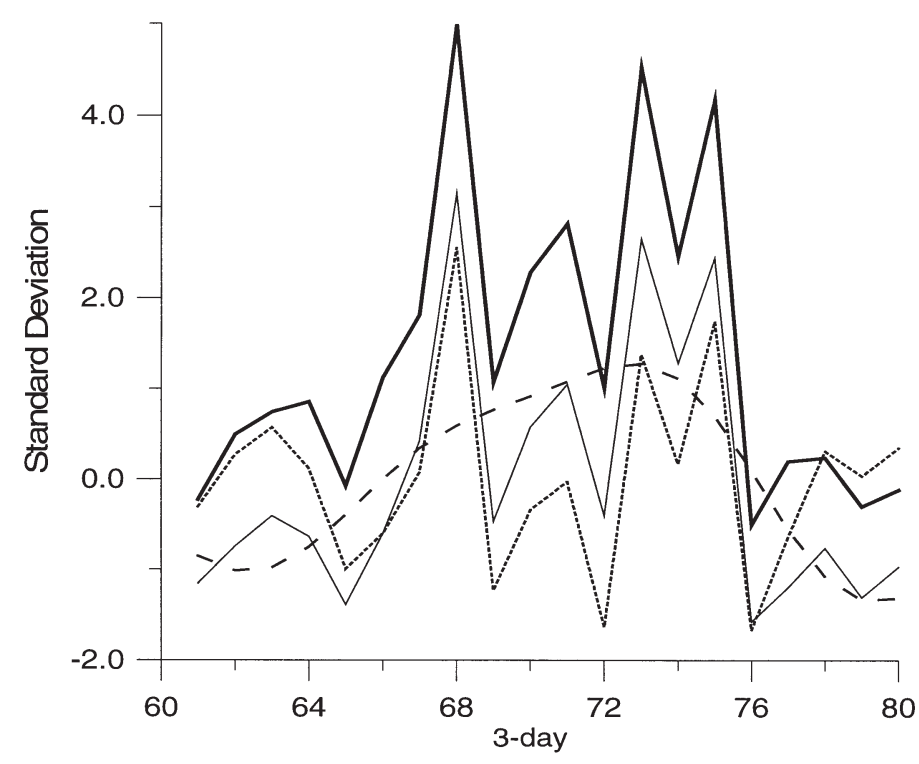

Fig. 12. Three day mean precipitation, 6-70D filtered, 6-20D (weekly), 25-70D (intraseasonal) precipitation during July-August (P61-80) 1996 in northern China. Lines as in Fig. 10

Japan) and a negative center over the central northern Pacific Ocean (Fig. 11c). The intraseasonal time scale precipitation is correlated with atmospheric anomalies over 4 scattered places in western Eurasia, northwestern Siberia, the northern North Pacific and the Arctic Ocean (Fig. 11d). It is clear that the atmospheric anomaly centers associated with the weekly precipitation component coincide with those associated with $3 \mathrm{~d}$ mean precipitation. In other words, weekly precipitation variability captures most of the atmospheric anomalies associated with $3 \mathrm{~d}$ mean precipitation.

The time series of the standardized $3 \mathrm{~d}$ mean precipitation and filtered components of the 6-70D, weekly, and intraseasonal time scale precipitation components during July-August in 1996 are shown in Fig. 12. The weekly precipitation component captures the peaks of 3 d mean precipitation (Fig. 12).

The significant correlations between $3 \mathrm{~d}$ mean precipitation and $500 \mathrm{mb}$ geopotential height is concentrated in southeastern China (Fig. 13a) although the general correlation pattern resembles that of 1994 (Fig. 11a). Again, the 6-70D filtered precipitation captures most features of the $500 \mathrm{mb}$ geopotential height anomalies (Fig. 11b). The correlation map associated with the weekly component of precipitation rather than that for the intraseasonal component captures the atmospheric circulation anomaly patterns associated with the $3 \mathrm{~d}$ mean precipitation. It has a general pattern similar to 1994: positive centers around Lake Baikal and the Sea of Japan and a negative center over the central northern Pacific, although the first and the last centers are not shown to be statistically significant at a $95 \%$ confidence level. This suggests that the circulation anomaly over the Sea of Japan plays an important role in weekly time scale summer precipitation variations during wet seasons in northern China.

\subsection{Association with intraseasonal precipitation variation over Southern China during the rainy season (May to June) in 1968 and 1994}

The time series of $3 \mathrm{~d}$ mean and 6-70D filtered, weekly, and intraseasonal components for 1968 are shown in Fig. 14. The intraseasonal precipitation component contributes most of the $3 \mathrm{~d}$ mean precipitation in the second half of June (P54-59). The $3 \mathrm{~d}$ mean precipitation and 6-70D filtered precipitation components are correlated to $500 \mathrm{mb}$ geopotential height anomalies over the Arctic Ocean and the western tropical North Pacific (Fig. 15a,b). The correlation map associated with the intraseasonal precipitation component (Fig. 15d) instead of the weekly precipitation component captures the $500 \mathrm{mb}$ geopotential height anomaly centers associated with 3 d mean precipitation.

The time series of $3 \mathrm{~d}$ mean precipitation and different time scale components for 1996 are shown in Fig. 16. The intraseasonal time scale component during the second half of June (P54-58) contributes most to $3 \mathrm{~d}$ mean precipitation. The correlation coefficients map between $3 \mathrm{~d}$ mean precipitation and $500 \mathrm{mb}$ geopotential height heights has some similarity to that of 1968 (Fig. 17a). The major centers are northern central Siberia, the northwestern Pacific, and an area around eastern Siberia and Alaska. Again, the correlation map of 6-70D resembles that of $3 \mathrm{~d}$ mean precipitation (Fig. 17b). The correlation map associated with the intraseasonal component has one center over northern central Siberia and one over the western tropical Pacific Ocean (Fig. 17d), and the map associated with the weekly component captures the other 2 centers over the northwestern Pacific and the area around eastern Siberia and Alaska (Fig. 17c). The only common center associated with intraseasonal precipitation components for both years (1968 and $1994)$ is the one over the western tropical North Pacific (Figs. 15c \& 17c). This suggests that the strength of tropical high pressure over the western Pacific is associated with heavy rainfall and intraseasonal precipitation variability over southern China. This is consistent with other studies that found that intraseasonal oscillations are present in the subtropical high over the tropical western Pacific (Madden \& Julian 1972, Lau \& Philips 1986, Wang \& Xu 1997, Unda \& Yasunari 1998). 

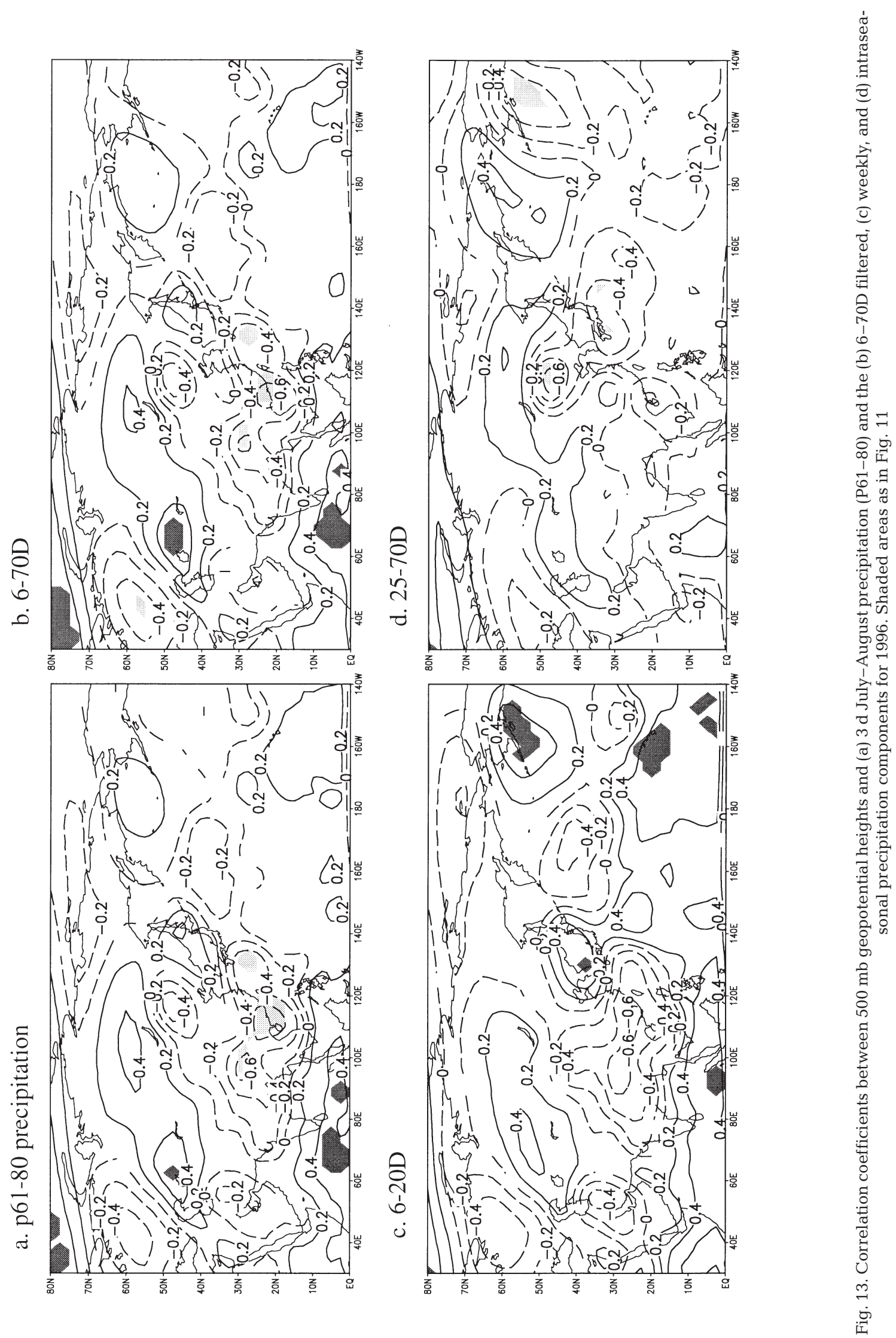


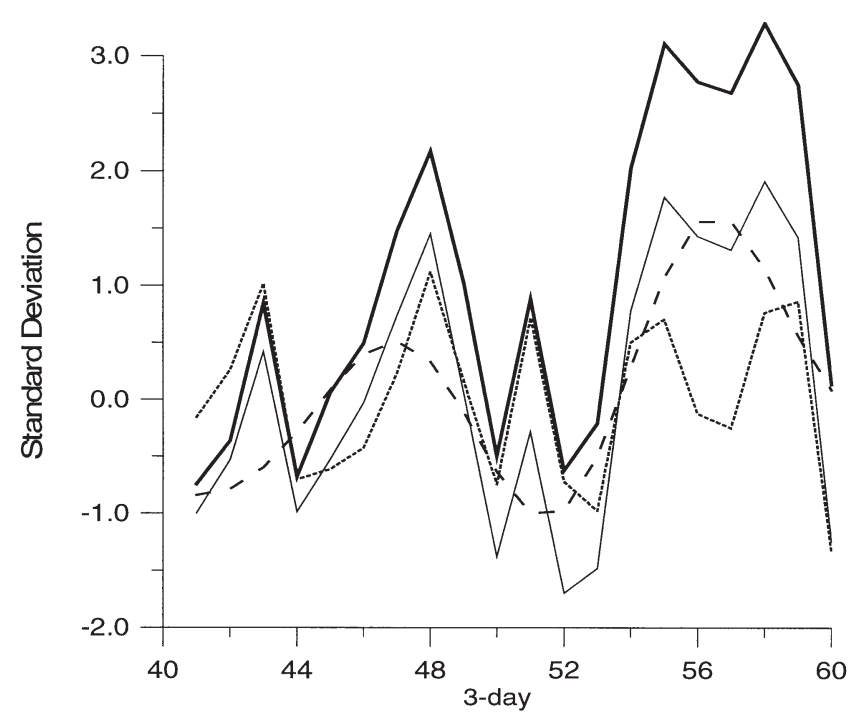

Fig. 14. Three day mean precipitation and the 6-70D filtered, 6-20D (weekly), and 25-70D (intraseasonal) precipitation components during May-June (p4l-60), 1968, in southern China. Lines as in Fig. 10

\section{CONCLUSIONS}

Multi time scale characteristics of summer precipitation variation over eastern China and their associations with mid-tropospheric circulation were analyzed using $3 \mathrm{~d}$ mean precipitation at 76 stations during 1968-1997. The results are summarized as follows:

First, 2 distinct rainy seasons of July-August and May-June were found in northern and southern China, respectively. The $3 \mathrm{~d}$ mean precipitation is greater than $10 \mathrm{~mm}$ over northern China and is greater than $20 \mathrm{~mm}$ over southern China during these 2 rainy seasons. The rainy season mean precipitation over northern and southern China shows some similar decadal time scale variations. These 2 defined rainy seasons for northern and southern China correspond to the northern and southern branches of the East Asian monsoon, reflecting the different responses of regional precipitation to monsoon circulation.

Second, precipitation has a weekly time scale variation component at $7.2 \mathrm{~d}$ during the first half of August over northern China and an intraseasonal time scale variation of $25 \mathrm{~d}$ during the second half of June over southern China in wet seasons. This reflects the different precipitation structures over northern and southern China accompanied by 2 summer monsoon stages.

Third, precipitation anomalies during the first half of August over northern China (weekly time scale variation present) and those in the second half of June over southern China (intraseasonal time scale variation present) are the major contributors to the corresponding rainy season's total precipitation. It is evident that drought during the second half of June is responsible for low May-June precipitation totals, as exemplified by the dry years during the 1980s.

Fourth, the above-normal $500 \mathrm{mb}$ geopotential height over the Sea of Japan plays an important role in inducing heavy precipitation and is associated with weekly time scale variations over northern China during the rainy season. Over southern China, abnormal $500 \mathrm{mb}$ geopotential heights over the western tropical Pacific are associated with heavy precipitation and the intraseasonal time scale variation during the rainy season.

The summer rainfall in northern and southern China and its associations with atmospheric circulation are a complex problem. Future work will include an investigation of global and regional circulation background related to the long-term dry period during the 1980s over northern and southern China and the impacts of ENSO on summer rainfall variations.

Acknowledgements. The authors wish to thank Dr. A. N. Samel and Dr. X.-Z. Liang for providing daily precipitation data over China and A. B. Houser for editing the final version of this manuscript. This research is supported by the Natural Sciences and Engineering Research Council (NSERC) of Canada.

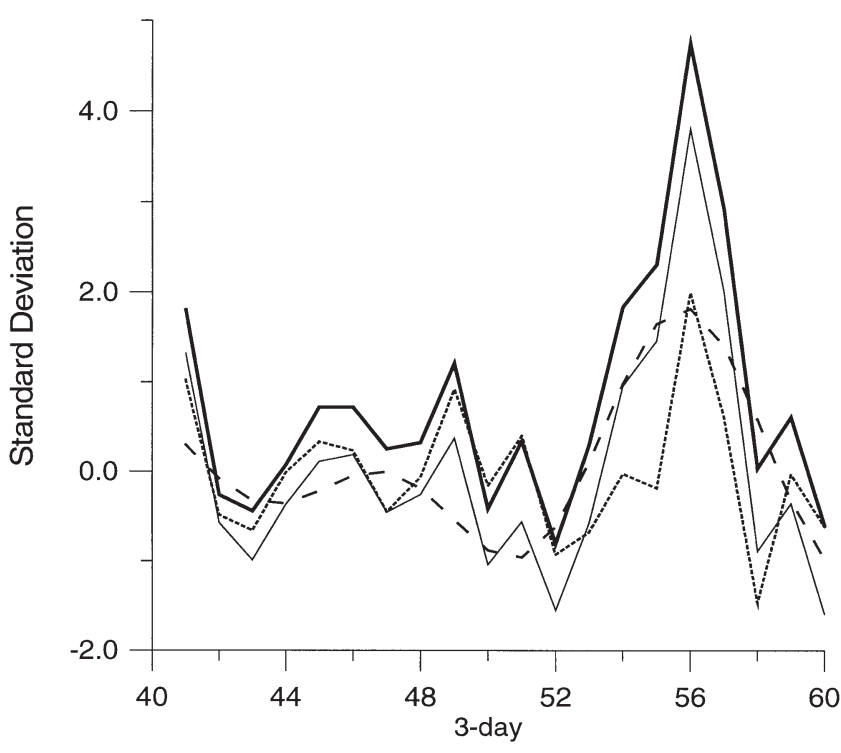

Fig. 16. Three day mean precipitation and the $6-70 \mathrm{D}$ filtered, 6-20D (weekly), and 25-70D (intraseasonal) precipitation components during May-June (p4l-60), 1994, in southern China. Lines as in Fig. 10 

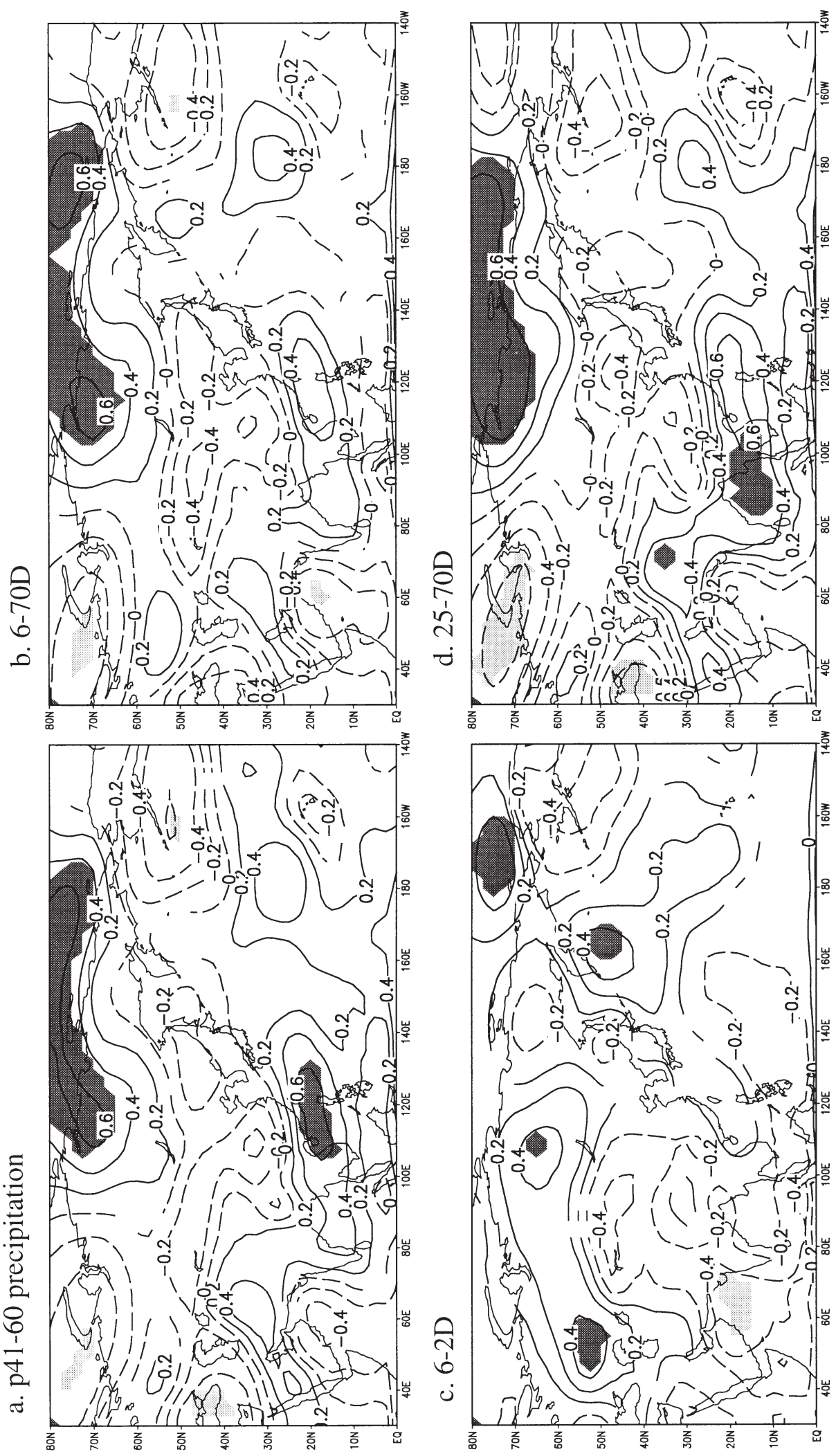

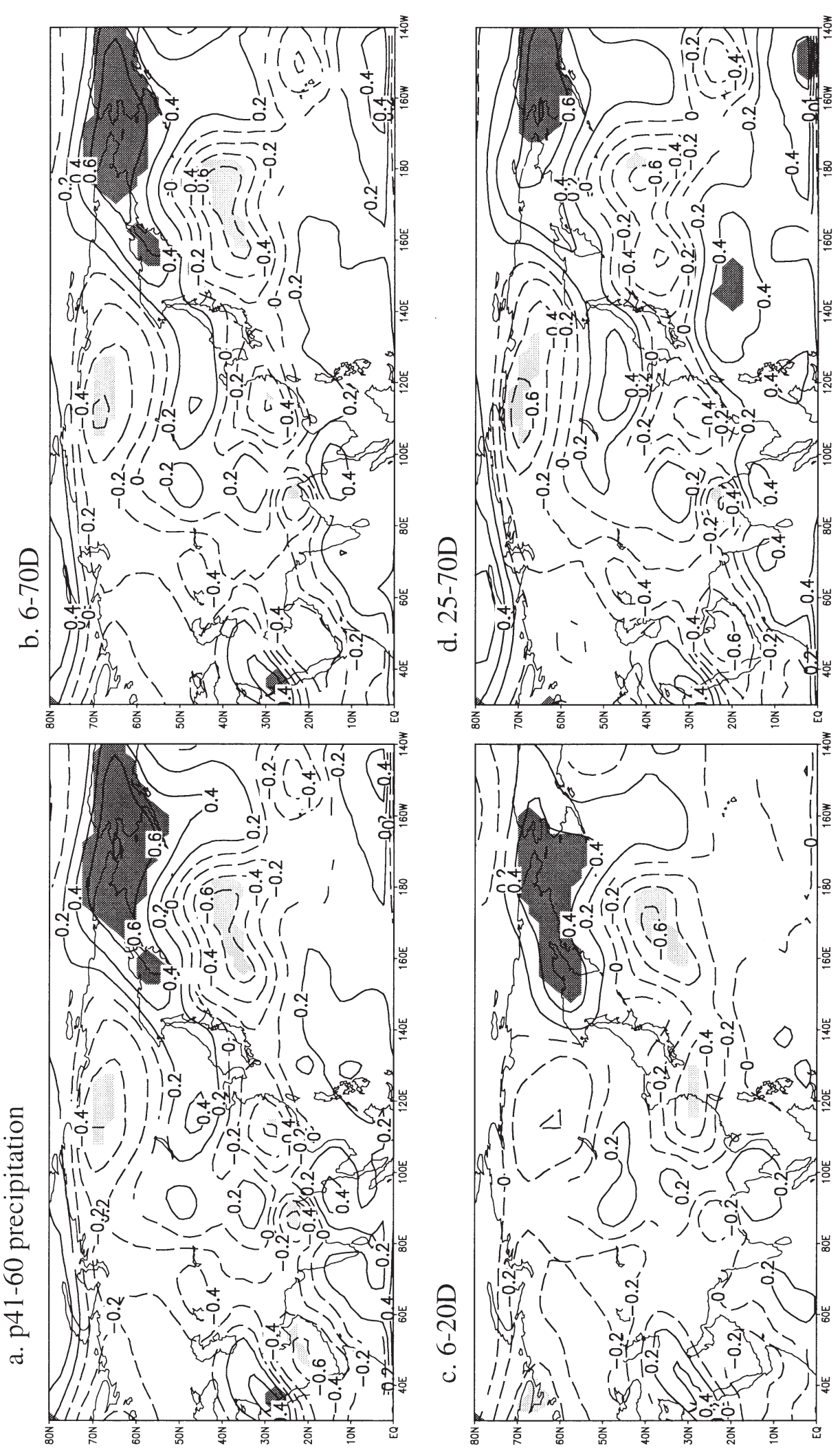

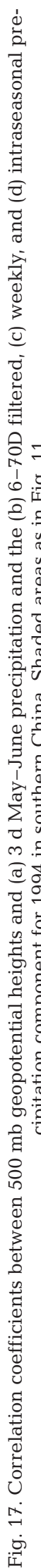


Appendix 1. Wavelet calculation details

For the Morlet WT, the mother wavelet is:

$$
\varphi_{0}(l)=\pi^{-1 / 4} \mathrm{e}^{\mathrm{i} \cdot W \cdot l} \mathrm{e}^{-l^{2} / 2}
$$

Wavenumber $w$ gives the number of oscillations, and here we choose $w=6$ for the Morlet WT.

A set of scaling parameters, $s$, contains the sample frequencies in our precipitation series. In the present study, we have $3 \mathrm{~d}$ data, thus $\mathrm{d} t=1(3 \mathrm{~d})$. The smallest wavelet resolved is $2 \mathrm{~d} t$, that is, $S_{0}=2 \mathrm{~d} t=2(6 \mathrm{~d})$. The larger scales are chosen as power-of- 2 multiples of this smallest scale:

$$
\begin{aligned}
& S_{i}=S_{0} \cdot 2^{i \cdot \delta i}, \quad i=0,1,2 \cdots \cdots, J \\
& I=\delta i^{-1} \log _{2}\left(N \cdot \delta t / S_{0}\right)
\end{aligned}
$$

The largest scale here is less than half the length of the entire time series.

On the basis of Eq. (A2), the WT is the convolution between the 2 functions $X$ and $\varphi$. Using Fast Fourier Trans- form (FFT), the WT can be realized:

$$
W_{n}(s)=\sum_{k=0}^{N-1} \hat{X}_{k} \cdot \hat{\varphi}^{*}\left(s \cdot W_{k}\right) \cdot \mathrm{e}^{i \cdot W_{k} \cdot n \cdot \delta t}
$$

where ${ }^{\wedge}$ indicates the FT. The FT of the time series is obtained using:

$$
\hat{X}_{k}=\frac{1}{N} \cdot \sum_{n=0}^{N-1} X_{n} \cdot \mathrm{e}^{-2 \pi \cdot i \cdot k \cdot n / N}
$$

In this case, the reconstructed time series is the sum of the real part $(\Re)$ of the WTs over all scales:

$$
X_{n}=\frac{\delta i \cdot \delta t^{1 / 2}}{C_{\delta} \cdot \varphi_{0}(0)} \cdot \sum_{i=0}^{I} \frac{(\Re)\left\{W_{n}\left(s_{i}\right)\right\}}{s_{i}^{1 / 2}}
$$

The factor $\varphi_{0}(0)$ removes the energy scaling, and $c_{\delta}$ comes from the reconstruction of a $\delta$ function from its wavelet transform using the function $\varphi_{0}(l)$; the $c_{\delta}$ is 0.766 for the Morlet wavelet.

\section{LITERATURE CITED}

Bao ZH, Mikami T (1998) Summer rainfall anomalies in the Yangtze Valley and the middle reaches of the Yellow River in China and their association with the atmosphericoceanic circulation indices from 1951 to 1991. Geogr Rev Jpn 71B: 59-71

Chapa SR, Rao VB, Prasad GS (1998) Application of wavelet transform to Meteosat-derived cold cloud index data over South America. Mon Weather Rev 126:2466-2481

Chen G, Hsu YS (1997) Composite structure of a low-level jet over Southern China observed during the TAMEX period. J Meteorol Soc Jpn 75:1003-1018

Chen L, Dong M, Shao Y (1992) The characteristics of interannual variation on the East Asian monsoon. J Meteorol Soc Jpn 70:397-421

Chen TC, Chen JM (1995) An observational study of the South China Sea monsoon onset and life cycle. Mon Weather Rev 123:2295-2318

Ding YH (1991) Advanced synoptic meteorology. Meteorology Press, Peking

Ding YH (1992) Summary monsoon rainfall in China. J Meteorol Soc Jpn 70:373-398

Ding YH (1994) Monsoon over China. Kluwer Academic Publishers, Dordrecht

Fu C, Fletcher JO (1988) Large signals of climatic variation over the ocean in the Asian monsoon region. Adv Atmos Sci 5:389-404

Gamage N, Blumen C (1993) Detection and analysis of microfronts and associated coherent events using localized transforms. J Atmos Sci 50:750-756

Kalnay EM and 24 others (1996) The NCEP/NCAR 40-year reanalysis project. Bull Am Meteorol Soc 77:437-471

Krishnakumar J, Lau KM (1998) Possible role of symmetric instability in the onset and abrupt transition of the Asian monsoon. J Meteorol Soc Jpn 76:363-383

Lau KM, Philips TJ (1986) Coherent fluctuation of extratropical geopotential heights and tropical convection in intraseasonal timescales. J Atmos Sci 43:3333-3350

Lau KM, Weng HY (1995) Climate signal detection using wavelet transform: how to make a time series sing. Bull Am Meteorol Soc 76:2391-2402

Lau KM, Yang S (1996) Seasonal variation, abrupt transition, and intraseasonal variability associated with the Asian summer monsoon in the GLA GCM. J Clim 9:965-985

Lau KM, Yang GJ, Shen SH (1988) Seasonal and intraseasonal climatology of summer monsoon rainfall over East Asia. Mon Weather Rev 116:18-37

Liang XZ, Wang WC (1995) Observed and GCM simulated decade variability of monsoon rainfall in east China. Clim Dyn 11:103-114

Madden RA, Julian PR (1972) Description of global-scale circulation cells in the tropics with 1 40-50 day period. J Atmos Sci 29:1109-1123

Mahrt L (1991) Eddy asymmetry in the sheared heated boundary layer. J Atmos Sci 48:472-494

Meyers SD, Kelly BG, O'Brien JJ (1993) An introduction to wavelet analysis in oceanography and meteorology: with application to the dispersion of Yanai waves. Mon Weather Rev 121:2858-2866

Morlet J (1983) Issues in acoustic signal/image processing and recognition. In: Chen $\mathrm{CH}$ (ed) Sampling theory and wave propagation. NATO ASI Series, Springer-Verlag, Heidelberg, p 233-261

Murakami T, Matsumoto J (1994) Summer Monsoon over the Asian continent and western North Pacific. J Meteorol Soc Jpn 72:719-745

Nitta T, Hu ZZ (1996) Summer climate variability in China and its association with $500 \mathrm{hPa}$ heights and tropical convection. J Meteorol Soc Jpn 74:425-445

Richman MB (1986) Rotation of principal components. J Climatol 6:293-335

Richman MB (1987) Rotation of principal components: a reply. J Climatol 7:511-520

Samel AN, Wang WC, Liang XZ (1999) The monsoon rainband over China and relationships with the Eurasian circulation. J Clim 12:115-131

Tao S, Chen L (1987) A review of recent research on the East Asia summer monsoon in China. Chang CP, Krishnamurti TN (eds) Monsoon meteorology. Oxford University Press, Oxford, p 60-92

Tao S, Fu C, Zeng Z, Zhang QY (1991) Two long-term instrumental climate data bases of the Peoples Republic of China. Publication 3747, Environmental Sciences Division, DOE (available from Carbon Dioxide Information Analysis Center, Oak Ridge National Laboratory, Oak Ridge, TN 37831-6335, USA)

Torrence C, Compo GP (1998) A practical guide to wavelet 
analysis. Bull Am Meterol Soc 79:61-78

Unda H, Yasunari T (1998) Role of warming over the Tibetan Plateau in early onset of the summer monsoon over Bay of Bengal and the South China Sea. J Meteorol Soc Jpn 76: $1-12$

von Storch H, Zwiers FW (1999) Analysis of climate variability: applications of statistical techniques, 2nd edn. Springer, New York

Wang B, Wu R (1997) Peculiar temporal structure of the South China Sea summer monsoon. Adv Atmos Sci 14:177-194

Wang B, Xu X (1997) Northern Hemisphere summer monsoon singularities and climatological intraseasonal oscillation. J Clim 10:1071-1085

Wang SW, Zhao ZC (1981) Droughts and floods in China, 1470-1979. In: Wigley TML, Ingram MJ, Farmer G (eds) Climate and history. Cambridge University Press, Cambridge, p 271-288

Wang WC, Li K (1990) Precipitation fluctuation over semiarid regions in northern China and relationship with El Nino/ Southern Oscillation. J Clim 3:769-783

Wang X, Corte-Real J, Zhang X (1996) Interseasonal oscillations and associated spatial temporal structures of precip-

Editorial responsibility: Laurence Kalkstein,

Newark, Delaware, USA itation over China. J Geophys Res 101(D14):19035-19042

Webster PJ, Yang S (1992) Monsoon and ENSO: selectively interactive systems. Q J R Meteorol Soc 118:877-926

Weng HY, Lau KM (1994) Wavelets, period doubling, and time-frequency localization with application of convective over the tropical western Pacific. J Atmos Sci 51: $2523-2541$

Yasunari T (1991) The monsoon year-a new concept of the climatic year in the tropics. Bull Am Meteorol Soc 72: 1331-1338

Yatagai A, Yasunari T (1994) Trends and decadal-scale fluctuations of surface air temperature and precipitation over China and Mongolia during the recent 40-year period (1951-1990). J Meteorol Soc Jpn 72:937-957

Yatagai A, Yasunari T (1995) Interannual variations of summer precipitation in the arid/semi-arid regions in China and Mongolia: their regionality and relation to the Asian summer monsoon. J Meteorol Soc Jpn 73:909-923

Ye D (ed) (1987) The climate of China and global climate: proceedings of the Beijing International Symposium on Climate, Oct 30-Nov 3, 1984. China Beijin, Beijing; China Ocean Press, Berlin; and Springer-Verlag, New York

Submitted: August 8, 2001; Accepted: September 10, 2001 Proofs received from author(s): February 15, 2002 